\title{
Mobility and Academic Achievement for Texas Grade 7 Students: A Multiyear Investigation
}

\author{
Benjamin Mark Bostick ${ }^{1}$, John R. Slate ${ }^{2}$ \\ ${ }^{1}$ Spring Independent School District \\ ${ }^{2}$ Sam Houston State University \\ Email: profslate@aol.com
}

\begin{abstract}
Differences in reading, mathematics, and writing achievement of Grade 7 students as a function of mobility were examined with and without controls for economic status in this investigation. Data were obtained from the Texas Education Agency Public Education Information Management System for the 2002-2003 through the 2007-2008 school years. Statistically significant differences were revealed in reading, mathematics, and writing test scores as a function of student mobility, both when controlling for and not controlling for economic status. Mobile students had statistically significantly lower reading, mathematics, and writing test scores than did non-mobile students for all 6 school years. Implications for policy and practice and suggestions for future research were made.
\end{abstract}

Keywords: Mobility, academic achievement, poverty, grade 7, texas.

\section{Introduction}

Families in the United States change residences frequently and for a multitude of reasons. The United States has been considered one of the most mobile countries in the industrialized world (Rumberger, 2003). Some mobility may be for preference, others for economic reasons. A family may move for a new job opportunity or due to a job loss. Families may move to be nearer extended family or other resources. Families may move due to new marriage or a divorce (Hartman 2003). Most moves, however, will result in a change of school for children in a family experiencing mobility. These school changes may have negative effects on students. Negative influences of mobility have been documented related to students' behavior (e.g., Gasper, DeLuca, \& Estacion, 2010), school persistence (e.g., Haveman \& Wolfe, 1994; Ross, 2014), and academics (e.g., Kain \& O'Brien, 1998; Smith, Fein, \& Paine, 2008); however, the persistence of negative effects of mobility on student academic performance, has not been firmly established (Bourque, 2009; Temple \& Reynolds, 1999).

Residential mobility is not the only cause of student mobility. School choice and school encouraged school changes may also cause students to change schools (Gasper et al., 2010). Areas with multiple charter, private, or parochial schools effectively have school choice. Some districts may also have magnet programs and policies allowing school choice. As student status changes or available transportation changes these students may change schools due to their own choice or a school's policy. Parents, students, and school administrators may choose to change a school believing they are making the best choice for the student; however, the long term effects of changing a school mid-year may not be understood.

\subsection{Purpose}

The purpose of this study was to analyze the relationship between student mobility and academic achievement for Grade 7 students in Texas while controlling for and not controlling for economic status (i.e., eligibility for the federal free and reduced lunch program). Specifically, academic achievement was measured by the Grade 7 Texas Assessment of Knowledge and Skills Reading, Mathematics, and Writing tests. Six school years of Texas statewide data were analyzed to determine the degree to which trends were present in the performance of mobile and non-mobile students. 


\section{$2 \quad$ Background}

Researchers (e.g., Bourque, 2009; Temple \& Reynolds, 1999) disagree on the lingering effects of mobility. Some researchers (e.g., Haynie, South, \& Bose, 2006) have documented that negative effects of mobility persist beyond two years after the move. Other researchers (e.g., Strand \& Demie; 2007; Temple \& Reynolds, 1999) indicated negative effects of mobility are eliminated after a short period of time, when controlling for demographic factors, or when prior academic achievement is considered (e.g., Reynolds, Chen, \& Herbers, 2009). At a minimum, mobility is connected to negative effects on behavior (e.g., Gasper et al., 2010), school persistence (e.g., Haveman \& Wolfe, 1994; Ross, 2014), and academics (e.g., Kain \& O'Brien, 1998; Smith et al., 2008). Mobile students may be less likely to participate in extracurricular activities in which better behavior, academic performance, and a reduced occurrence of school dropout have been documented (e.g., Lovell \& Isaacs, 2008; Pribesh \& Downey, 1999; Rumberger, Larson, Ream, \& Palardy, 1999). Students who move into a school during a school year or at the beginning of a school year but not with a common cohort (e.g., elementary school to junior high school), have also been reported to select a peer group with fewer pro-social behaviors. These poor social influences may lead to the mobile student exhibiting fewer pro-social behaviors (Schaller, 1975; Scherrer, 2013).

School administrators and policy makers have attempted to address the issues faced by mobile students in several different ways. Programs have been implemented to reduce mobility, allowing students to remain in a particular school for the entire year or longer (James \& Lopez, 2003). Programs designed to connect families to the school and provide information to parents have been utilized to encourage parents to delay moves if possible (Franke, Isken, \& Para, 2003; Kerbow, Azcoita, \& Buell, 2003). In situations where mobility cannot be avoided or delayed, programs have been implemented to reduce the negative effects of mobility on students (Smith et al., 2008).

Programs that allow students flexibility in which school they attend can contribute to student mobility or reduce student mobility. School districts with flexible enrollment policies give students who experience residential mobility the opportunity to remain in the school so that they begin the school year in which can reduce their mobility rate. Students who qualify as homeless are guaranteed this ability under the McKinney-Vento Homeless Education Act (James \& Lopez, 2003). Some districts also extended transportation services to students to encourage remaining in the same school for a full school year (Julianelle \& Foscarinis, 2003). Parents and educators alike may not understand the long term effects of student mobility, and therefore may choose to have students change schools when their move can be avoided. Schools in areas with high mobility and a high number of low economic status students have implemented programs designed to connect families to schools. These programs may include programs to provide health services, nutrition services, or summer activity programs (Franke et al., 2003; Smith et al., 2008). Researchers (e.g., Hanushek, Kain, \& Rivkin, 2004, 2009) have provided data indicating that moves within a school district do not produce an increase in school quality and have increased negative effects.

By implementing programs targeted towards mobile students, school administrators can reduce the negative effects of mobility when a school change is unavoidable. Mobile students may experience a disjointed curriculum. Gaps in curriculum due to poor alignment between the school the student left and the school the student entered can be addressed through immediate and efficient assessment of students entering a school (Branz-Spall, Rosenthal, \& Wright, 2003; Smith et al., 2008; Smrekar \& Owens, 2003). Efficient methods of exchanging information regarding incoming students enable students to be placed immediately in to programs to meet their needs, giving teachers needed information about any academic gaps that may exist (Smrekar \& Owens, 2003). The common practice of aligning curriculum among buildings within a school district can be extended between school districts to assist mobile students. In areas where regular patterns of mobility exist, curricular alignment between schools has been determined to mitigate the negative academic effects on mobile students (Bradshaw, Sudhinaraset, Mmari, \& Blum, 2010; Kerbow et al., 2003; Rumberger, 2003). Students who are attending the schools that mobile students enter can also assist students as they enroll. Pairing students with a student ambassador can help students make pro-social peer connections and reduce the disorientation that can come with changing schools (Kerbow et al., 2003; Smrekar \& Owens, 2003). 


\subsection{Significance of the Study}

Research undertaken in which the link between academic achievement and student mobility has been investigated has produced varying results due to varying methods and controls. Small sample sizes also reduce the generalizability of many published studies. Data for this study were taken from all students who took the Grade 7 Texas Assessment of Knowledge and Skills tests in 2003 through 2008. This sample provided adequate size to obtain statistically significant results and the ability to control for economic status.

Research undertaken on the subject of student mobility has not produced consistent results (e.g., Bourque, 2009; Temple \& Reynolds, 1999). However, researchers (e.g., Bruno \& Isken, 1996; Gasper et al., 2010; Ross, 2014) indicate mobility is at least linked to negative school outcomes. Mobility can be caused by multiple factors and can be categorized in various ways including mobility between school years and during school years (Rumberger, 2003). For this empirical investigation, the Texas Education Agency definition of mobility was used. Students who are enrolled in a school for less than $83 \%$ of the school year are considered mobile (Texas Education Agency, 2012). Utilizing this definition, most residential moves that occur during the school year were captured. School required moves, school encouraged moves, and mobility related to school choice when the mobility occurs during the school year was also captured. Students experiencing mobility during the school year may have experienced differences in curriculum, school structures, and school culture, which could have caused a disorienting effect for mobile students (Rumberger, 2003). Frequent mobility could have also caused students to become less connected to the school they attend or prevented them from participating in activities such as extracurricular programs that foster school connectedness (Scherrer, 2013).

Differences in the outcomes of research regarding mobility can be attributed to differences in sampling and controls for confounding variables. In this research study, the negative effects of mobility were investigated while controlling for economic status. Included in the sample were all students who took the Texas Assessment of Knowledge and Skills Reading, Mathematics, and Writing tests in Texas during Grade 7 between the 2003 and 2008 school years. Through obtaining such a large sample size, issues of small sample size encountered when sampling within individual school districts was addressed. This sample size also allowed for controls for economic status.

\section{$2.2 \quad$ Research Questions}

The three subject areas assessed in the state-mandated tests at Grade 7 were investigated in this study. The research questions related to reading were: (a) What is the relationship of student mobility to Grade 7 reading achievement when controlling for economic status?; and (b) What is the relationship of student mobility to Grade 7 reading achievement when not controlling for economic status? The research questions related to mathematics were: (a) What is the relationship of student mobility to Grade 7 mathematics achievement when controlling for economic status?; and (b) What is the relationship of student mobility to Grade 7 mathematics achievement when not controlling for economic status? Finally, the research questions concerning writing were: (a) What is the relationship of student mobility to Grade 7 writing achievement when controlling for economic status?; and (b) What is the relationship of student mobility to Grade 7 writing achievement when not controlling for economic status? These research questions were repeated for each of the 6 school years of data analyzed.

\section{$3 \quad$ Method}

\subsection{Participants}

The specific focus of this study was on determining the extent to which differences were present in academic achievement between mobile and non-mobile students in Grade 7. To analyze these differences, archival data from the Texas Education Agency Public Education Information Management System for all Grade 7 students during the 2002-2003 to the 2007-2008 school years were collected. This archival dataset included data for 297,292 Grade 7 students during the 2002-2003 school year, 307,871 Grade 7 students during the 2003-2004 school year, 310,928 Grade 7 students during the 2004-2005 school year, 312,137 Grade 7 students during the 2005-2006 school year, 306,237 Grade 7 students during the 2006- 
2007 school year, and 355,041 Grade 7 students during the 2007-2008 school year.

Grade 7 Texas Assessment of Knowledge and Skills Reading, Mathematics, and Writing Test raw scores from 2003 to 2008 were analyzed as the dependent variables for this study. Readers should examine the technical reports for these tests for specific score validity and score reliability information. These reports are available through a Public Information Request to the Texas Education Agency.

\subsection{Research Design}

Because archival data were analyzed in this research study, a non-experimental research design was used (Johnson \& Christensen, 2008). The independent variable in this study, mobility (i.e., enrollment in a school less than $83 \%$ of the school year), had already occurred (Texas Education Agency, 2012). For the purpose of this investigation the Texas Education Agency definition of mobility was utilized. Although the use of archival data precludes random group assignment, the use of archival data allows for a large sample size which produced adequate statistical power. Three dependent variables were utilized in this study: (a) academic achievement in reading, (b) academic achievement in mathematics, and (c) academic achievement in writing. Academic achievement for the purpose of this study was measured by raw scores on the Texas Assessment of Knowledge and Skills Reading, Mathematics, and Writing tests during the Grade 7 year. One control variable, student economic status, was utilized in this study. The Texas Education Agency (2012) definition of economic disadvantage, eligibility for the federal free and reduced lunch program or other public assistance, was utilized in this investigation.

\subsection{Data Analysis}

To address research question (a) for each of the three subjects tested in Texas at Grade 7, a Multivariate Analysis of Covariance (MANCOVA) statistical analysis was utilized. Underlying assumptions of normality and equality of variance for the dependent variables (i.e., Grade 7 Texas Assessment of Knowledge and Skills Reading, Mathematics, and Writing raw scores) were checked. Field (2009) stated, however, even if these assumptions have not been met the MANCOVA procedure is robust enough to provide reliable results. Grade 7 Texas Assessment of Knowledge and Skills Reading, Mathematics, and Writing test raw scores were each used as dependent variables in this study. The mean difference between each comparison was examined to determine the effect of the independent variable on the dependent variable when economic status was controlled.

To address research question (b) for each of the three subjects tested in Texas at Grade 7 a Multivariate Analysis of Variance (MANOVA) statistical analysis was utilized. The MANOVA statistical analysis was utilized due to the presence of multiple dependent variables (i.e., Grade 7 Texas Assessment of Knowledge and Skills Reading, Mathematics, and Writing Test raw scores) and no control variables. Underlying assumptions of normality were checked for the dependent variables as they were in the MANCOVA analysis. Field (2009) supports the use of MANOVA analyses even when the underlying assumptions were not met.

\section{$4 \quad$ Results}

Results of the statistical analysis for Grade 7 mobile and non-mobile students will be reported by TAKS subject area subtest (i.e., Reading, Mathematics, and Writing). Results of each test will be reported in chronological order. Research question a for each subject area requires a MANCOVA procedure to consider economic status as a covariate and is reported first. Research question b for each subject area requires a MANOVA procedure and is reported second. Data from the 2002-2003 through the 2007-2008 school years were analyzed herein.

As noted previously, student economic status was used as a covariate in research question a for each subject area. For these research questions, a MANCOVA statistical procedure was calculated. A statistically significant difference was yielded on student overall achievement, Wilks' $\Lambda=1.0, p<.001$, partial $\eta^{2}=.002$, trivial effect size, as a function of student mobility, and as a function of student poverty, Wilks' $\Lambda=.84, p<.001$, partial $\eta^{2}=.16$, large effect size (Cohen, 1988). Readers should note the strong influence of poverty on student achievement in this analysis. A statistically significant 
difference was present between the covariate of economic status and TAKS Reading scores, $F(1,216894)$ $=34163.02, p<.001, r=.37$; between the covariate of economic status and TAKS Mathematics scores, $F(1,216894)=33125.11, p<.001, r=.37$; and between the covariate of economic status and TAKS Writing scores, $F(1,216894)=26826.49, p<.001, r=.33$. After controlling for the effect of economic status, a statistically significant effect of mobility was present for the TAKS Reading scores, $F(1$, $216894)=145.11, p<.001$, partial $\eta^{2}=.001$ TAKS Mathematics scores, $F(1,216894)=175.22, p$ $<.001$, partial $\eta^{2}=.001$, and for the TAKS Writing scores, $F(1,216894)=139.97, p<.001$, partial $\eta^{2}$ $=.001$.

The MANOVA completed for research question b for each subject area revealed a statistically significant difference between mobile and non-mobile Grade 7 students in their overall achievement, Wilks' $\Lambda=1.0, p<.001$, partial $\eta^{2}=.002$, trivial effect size (Cohen, 1988). Follow-up Analysis of Variance (ANOVA) procedures also yielded statistically significant differences between mobile and nonmobile Grade 7 students in their TAKS Reading performance, $F(1,216895)=268.38, p<.001$, partial $\eta^{2}=.001$; in their TAKS Mathematics performance, $F(1,216895)=303.78, p<.001$, partial $\eta^{2}=.001$; and in their TAKS Writing performance, $F(1,216895)=205.31, p<.001$, partial $\eta^{2}=.001$.

Non-mobile students had higher average TAKS Reading, Mathematics, and Writing test scores in the 2002-2003 school year than their mobile counterparts. These results remained even when controlling for economic status. Cohen's $d$ indicated a small effect size for reading (i.e., 0.25), mathematics (i.e., 0.28), and writing (i.e., 0.24; Cohen, 1988). The average TAKS Reading test raw score for mobile students was 1.93 points lower than the average TAKS Reading test raw score for non-mobile students. With respect to the TAKS Mathematics exam, the average raw score for mobile students was 2.57 points lower than the average raw score for non-mobile students. Concerning the TAKS Writing exam, the average raw score for mobile students was 1.66 points lower than the average raw score for non-mobile students. Delineated in Table 1 are the descriptive statistics for Grade 7 TAKS Reading, Mathematics, and Writing scores by mobility and economic status for the 2002-2003 school year.

Table 1. Descriptive statistics for grade 7 TAKS reading, mathematics, and writing tests for mobile and nonmobile students for the 2002-2003 school year

\begin{tabular}{l|l|l|l}
\hline TAKS Test by Mobility Status & $n$ & $M$ & $S D$ \\
\hline Reading & & & \\
\hline Non-Mobile & 212,766 & 37.17 & 7.48 \\
\hline Mobile & 4,128 & 35.24 & 8.03 \\
\hline Mathematics & & & \\
\hline Non-Mobile & 212,766 & 29.46 & 9.38 \\
\hline Mobile & 4,128 & 26.89 & 8.93 \\
\hline Writing & & & \\
\hline Non-Mobile & 212,766 & 30.75 & 6.65 \\
\hline Mobile & 4,128 & 29.09 & 7.06 \\
\hline
\end{tabular}

As noted previously, student economic status was used as a covariate in research question a for each subject area for the 2003-2004 school year. For these research questions, a MANCOVA statistical procedure was calculated. A statistically significant difference was yielded on student overall achievement, Wilks' $\Lambda=1.0, p<.001$, partial $\eta^{2}=.002$, trivial effect size, as a function of student mobility, and as a function of student poverty, Wilks' $\Lambda=.85, p<.001$, partial $\eta^{2}=.15$, large effect size (Cohen, 1988). Similar to the previous year, poverty had a large influence on student achievement. A statistically significant difference was present between the covariate of economic status and TAKS Reading scores, $F(1,226183)=29858.48, p<.001, r=.34$; TAKS Mathematics scores, $F(1,226183)=$ $32504.23, p<.001, r=.36$; and TAKS Writing scores, $F(1,226183)=29840.14, p<.001, r=.34$. After controlling for the effect of economic status, a statistically significant effect of mobility was still present for TAKS reading scores, $F(1,226183)=248.81, p<.001$, partial $\eta^{2}=.001$; TAKS Mathematics scores, $F(1,226183)=391.68, p<.001$, partial $\eta^{2}=.002$; and for TAKS Writing scores, $F(1,226183)=$ $270.35, p<.001$, partial $\eta^{2}=.001$.

With respect to research question $b$ for each subject area, the MANOVA revealed a statistically 
significant difference between mobile and non-mobile Grade 7 students in their overall achievement, Wilks' $\Lambda=1.0, p<.001$, partial $\eta^{2}=.003$, trivial effect size (Cohen, 1988). Follow-up ANOVA procedures also yielded statistically significant differences between mobile and non-mobile Grade 7 students in their TAKS Reading performance, $F(1,226183)=527.65, p<.001$, partial $\eta^{2}=.002$; in their TAKS Mathematics performance, $F(1,226183)=727.09, p<.001$, partial $\eta^{2}=.003$; and in their TAKS Writing performance, $F(1,226183)=556.87, p<.001$, partial $\eta^{2}=.002$.

Similar to the previous year, non-mobile students had higher average TAKS Reading, Mathematics, and Writing test scores in 2004 than their mobile counterparts. These results remained even when controlling for economic status. Cohen's $d$ indicated a small effect size for reading (i.e., 0.33), mathematics (i.e., 0.41), and writing (i.e., 0.35; Cohen, 1988). The average TAKS Reading test raw score for mobile students was 2.65 points lower than the average TAKS Reading test raw score for nonmobile students. Regarding the TAKS Mathematics exam, the average raw score for mobile students was 3.67 points lower than the average raw score for non-mobile students. With respect to the TAKS Writing exam, the average raw score for mobile students was 2.42 points lower than the average raw score for non-mobile students. Revealed in Table 2 are the descriptive statistics for Grade 7 TAKS Reading, Mathematics, and Writing scores by mobility and economic status for the 2003-2004 school year.

Table 2. Descriptive statistics for grade 7 TAKS reading, mathematics, and writing tests for mobile and nonmobile students for the 2003-2004 school year

\begin{tabular}{l|l|l|l}
\hline TAKS Test by Mobility Status & $n$ & $M$ & $S D$ \\
\hline Reading & & & \\
\hline Non-Mobile & 221,678 & 38.38 & 7.64 \\
\hline Mobile & 4,505 & 35.73 & 8.48 \\
\hline Mathematics & & & \\
\hline Non-Mobile & 221,678 & 31.16 & 9.07 \\
\hline Mobile & 4,505 & 27.49 & 8.79 \\
\hline Writing & & & \\
\hline Non-Mobile & 221,678 & 30.90 & 6.80 \\
\hline Mobile & 4,505 & 28.48 & 7.11 \\
\hline
\end{tabular}

Concerning the 2004-2005 school year, student economic status was used as a covariate in research questions a for each subject area. For these research questions, a MANCOVA statistical procedure was calculated. A statistically significant difference was yielded on student overall achievement, Wilks' $\Lambda=$ $1.0, p<.001$, partial $\eta^{2}=.002$, trivial effect size, as a function of student mobility, and as a function of student poverty, Wilks' $\Lambda=.85, p<.001$, partial $\eta^{2}=.16$, large effect size (Cohen, 1988). Congruent with the previous two years, poverty had a large influence on student achievement. A statistically significant difference was present between the covariate of economic status and TAKS Reading scores, $F(1,228422)=33665.56, p<.001, r=.36$; TAKS Mathematics scores, $F(1,228422)=35117.96, p$ $<.001, r=.37$; and TAKS Writing scores, $F(1,228422)=24637.70, p<.001, r=.31$. After controlling for the effect of economic status, a statistically significant effect of mobility was present for the TAKS reading scores, $F(1,228422)=365.21, p<.001$, partial $\eta^{2}=.002$; TAKS Mathematics scores, $F(1$, $228442)=470.09, p<.001$, partial $\eta^{2}=.002 ;$ and for the TAKS Writing scores, $F(1,228442)=324.11$, $p<.001$, partial $\mathrm{n}^{2}=.001$.

For research question $\mathrm{b}$ for each subject area, the MANOVA revealed a statistically significant difference between mobile and non-mobile Grade 7 students in their overall achievement, Wilks' $\Lambda=1.0$, $p<.001$, partial $\eta^{2}=.004$, trivial effect size (Cohen, 1988). Follow-up ANOVA procedures also yielded statistically significant differences between mobile and non-mobile Grade 7 students in their TAKS Reading performance, $F(1,228433)=619.66, p<.001$, partial $\eta^{2}=.003$; in their TAKS Mathematics performance, $F(1,228433)=751.83, p<.001$, partial $\eta^{2}=.003$; and in their TAKS Writing performance, $F(1,228433)=544.87, p<.001$, partial $\eta^{2}=.002$.

Similar to the two previous years, non-mobile students had higher average TAKS Reading, Mathematics, and Writing test scores in the 2004-2005 school year than their mobile counterparts. 
These results remained even when controlling for economic status. Cohen's $d$ indicated a small effect size for reading (i.e., 0.35), mathematics (i.e., 0.41), and writing (i.e., 0.32; Cohen, 1988). The average TAKS Reading test raw score for mobile students was 2.73 points lower than the average TAKS Reading test raw score for non-mobile students. Concerning the TAKS Mathematics exam, the average raw score for mobile students was 3.84 points lower than the average raw score for non-mobile students. Regarding the TAKS Writing exam, the average raw score for mobile students was 2.18 points lower than the average raw score for non-mobile students. Descriptive statistics for Grade 7 TAKS Reading, Mathematics, and Writing scores by mobility and economic status for the 2004-2005 school year are presented in Table 3.

Table 3. Descriptive statistics for grade 7 TAKS reading, mathematics, and writing tests for mobile and nonmobile students for the 2004-2005 school year

\begin{tabular}{l|l|l|l}
\hline TAKS Test by Mobility Status & $n$ & $M$ & $S D$ \\
\hline Reading & & & \\
\hline Non-Mobile & 223,867 & 38.87 & 7.32 \\
\hline Mobile & 4,555 & 36.41 & 8.40 \\
\hline Mathematics & & & \\
\hline Non-Mobile & 223,867 & 32.16 & 9.64 \\
\hline Mobile & 4,555 & 28.22 & 9.66 \\
\hline Writing & & & \\
\hline Non-Mobile & 223,867 & 33.08 & 6.25 \\
\hline Mobile & 4,555 & 30.90 & 7.18 \\
\hline
\end{tabular}

With respect to research question a for each subject area for the 2005-2006 school year, as noted previously, student economic status was used as a covariate in research questions a for each subject area. For these research questions, a MANCOVA statistical procedure was calculated. A statistically significant difference was yielded on student overall achievement, Wilks' $\Lambda=1.0, p<.001$, partial $\eta^{2}$ $=.004$, trivial effect size, as a function of student mobility, and as a function of student poverty, Wilks' $\Lambda=.85, p<.001$, partial $\eta^{2}=.15$, large effect size (Cohen, 1988). Congruent with the previous three years, poverty had a large influence on student achievement. A statistically significant difference was present between the covariate of economic status and TAKS Reading scores, $F(1,231671)=31484.75, p$ $<.001, r=.35$; TAKS Mathematics scores, $F(1,231671)=34300.69, p<.001, r=.37$; and TAKS Writing scores, $F(1,231671)=24004.68, p<.001, r=.31$. After controlling for the effect of economic status, a statistically significant effect of mobility remained for the TAKS Reading scores, $F(1,231671)$ $=604.38, p<.001$, partial $\eta^{2}=.003 ;$ TAKS Mathematics scores, $F(1,231671)=938.95, p<.001$, partial $\eta^{2}=.004$; and for the TAKS Writing scores, $F(1,231671)=494.34, p<.001$, partial $\eta^{2}=.002$.

For research question $b$ for each subject area, the MANOVA revealed a statistically significant difference between mobile and non-mobile Grade 7 students in their overall achievement, Wilks' $\Lambda=.99$, $p<.001$, partial $\eta^{2}=.006$, trivial effect size (Cohen, 1988). Follow-up ANOVA procedures also yielded statistically significant differences between mobile and non-mobile Grade 7 students in their TAKS Reading performance, $F(1,231671)=953.01, p<.001$, partial $\eta^{2}=.004$; in their TAKS Mathematics performance, $F(1,231671)=1347.32, p<.001$, partial $\eta^{2}=.006$; and in their TAKS Writing performance, $F(1,231671)=788.40, p<.001$, partial $\eta^{2}=.003$.

Similar to the previous three years, non-mobile students had higher average TAKS Reading, Mathematics, and Writing test scores in the 2005-2006 school year than their mobile counterparts. These results remained even when controlling for economic status. Cohen's $d$ indicated a small effect size for reading (i.e., 0.42), a moderate effect size for mathematics (i.e., 0.53), and a small effect size for writing (i.e., 0.37; Cohen, 1988). The average TAKS Reading test raw score for mobile students was 3.15 points lower than the average TAKS Reading test raw score for non-mobile students. Regarding the TAKS Mathematics exam, the average raw score for mobile students was 4.91 points lower than the average raw score for non-mobile students. Concerning the TAKS Writing exam, the average raw score for mobile students was 2.39 points lower than the average raw score for non-mobile students. Revealed in Table 4 are the descriptive statistics for Grade 7 TAKS Reading, Mathematics, Writing scores by 
mobility and economic status for the 2005-2006 school year.

Table 4. Descriptive statistics for grade 7 TAKS reading, mathematics, and writing tests for mobile and nonmobile students for the 2005-2006 school year

\begin{tabular}{l|l|l|l}
\hline TAKS Test by Mobility Status & $n$ & $M$ & $S D$ \\
\hline Reading & & & \\
\hline Non-Mobile & 226,938 & 39.39 & 6.92 \\
\hline Mobile & 4,733 & 36.24 & 8.20 \\
\hline Mathematics & & & \\
\hline Non-Mobile & 226,938 & 33.48 & 9.11 \\
\hline Mobile & 4,733 & 28.57 & 9.41 \\
\hline Writing & & & \\
\hline Non-Mobile & 226,938 & 34.42 & 5.79 \\
\hline Mobile & 4,733 & 32.03 & 6.99 \\
\hline
\end{tabular}

Regarding the 2006-2007 school year, as noted previously, student economic status was used as a covariate in research question a for each subject area. For these research questions, a MANCOVA statistical procedure was calculated. A statistically significant difference was yielded on student overall achievement, Wilks' $\Lambda=1.0, p<.001$, partial $\eta^{2}=.004$, trivial effect size, as a function of student mobility, and as a function of student poverty, Wilks' $\Lambda=.86, p<.001$, partial $\eta^{2}=.14$, large effect size (Cohen, 1988). Congruent with the previous four years, poverty had a large influence on student achievement. A statistically significant difference was present between the covariate of economic status and TAKS Reading scores, $F(1,228249)=32922.21, p<.001, r=.36$; TAKS Mathematics scores, $F(1$, $228249)=26517.71, p<.001, r=.33$; and TAKS Writing scores, $F(1,228249)=24802.06, p<.001, r$ $=.32$. After controlling for the effect of economic status, a statistically significant effect of mobility was present for the TAKS reading scores, $F(1,228249)=452.05, p<.001$, partial $\eta^{2}=.002$; TAKS Mathematics scores, $F(1,228249)=780.83, p<.001$, partial $\eta^{2}=.003$; and for the TAKS Writing scores, $F(1,228249)=453.15, p<.001$, partial $\eta^{2}=.002$.

For research question $b$ for each subject area, the MANOVA revealed a statistically significant difference between mobile and non-mobile Grade 7 students in their overall achievement, Wilks' $\Lambda=1.0$, $p<.001$, partial $\eta^{2}=.005$, trivial effect size (Cohen, 1988). Follow-up ANOVA procedures also yielded statistically significant differences between mobile and non-mobile Grade 7 students in their TAKS Reading performance, $F(1,228296)=713.15, p<.001$, partial $\eta^{2}=.003$; in their TAKS Mathematics performance, $F(1,228296)=1066.43, p<.001$, partial $\eta^{2}=.005$; and in their TAKS Writing performance, $F(1,228296)=688.51, p<.001$, partial $\eta^{2}=.003$.

Table 5. Descriptive statistics for grade 7 TAKS reading, mathematics, and writing tests for mobile and nonmobile students for the 2006-2007 school year

\begin{tabular}{l|l|l|l}
\hline TAKS Test by Mobility Status & $n$ & $M$ & $S D$ \\
\hline Reading & & & \\
\hline Non-Mobile & 224,513 & 38.99 & 6.59 \\
\hline Mobile & 3,736 & 36.08 & 7.79 \\
\hline Mathematics & & & \\
\hline Non-Mobile & 224,513 & 34.96 & 8.86 \\
\hline Mobile & 3,736 & 30.18 & 9.50 \\
\hline Writing & & & \\
\hline Non-Mobile & 224,513 & 34.38 & 5.10 \\
\hline Mobile & 3,736 & 32.17 & 6.12 \\
\hline
\end{tabular}

Similar to the previous four years, non-mobile students had higher average TAKS Reading, 
Mathematics, and Writing test scores in the 2006-2007 school year than their mobile counterparts. These results remained even when controlling for economic status. Cohen's $d$ indicated a small effect size for reading (i.e., 0.40), a moderate effect size for mathematics (i.e., 0.52), and a small effect size for writing (i.e., 0.39; Cohen, 1988). The average TAKS Reading test raw score for mobile students was 2.91 points lower than the average TAKS Reading test raw score for non-mobile students. Concerning the TAKS Mathematics exam, the average raw score for mobile students was 4.78 points lower than the average raw score for non-mobile students. Regarding the TAKS Writing exam, the average raw score for mobile students was 2.21 points lower than the average raw score for non-mobile students. Table 5 contains the descriptive statistics for Grade 7 TAKS Reading, Mathematics, and Writing scores by mobility and economic status for the 2006-2007 school year.

With respect to the 2007-2008 school year, as noted previously, student economic status was used as a covariate in research question a for each subject area. For these research questions, a MANCOVA statistical procedure was calculated. A statistically significant difference was yielded on student overall achievement, Wilks' $\Lambda=1.0, p<.001$, partial $\eta^{2}=.003$, trivial effect size, as a function of student mobility, and as a function of student poverty, Wilks' $\Lambda=.86, p<.001$, partial $\eta^{2}=.14$, large effect size (Cohen, 1988). Congruent with the previous five years, poverty had a large influence on student achievement. A statistically significant difference was present between the covariate of economic status and TAKS Reading scores, $F(1,240910)=30369.13, p<.001, r=.34$; TAKS Mathematics scores, $F(1$, $240910)=30812.54, p<.001, r=.34$; and TAKS Writing scores, $F(1,240910)=23568.17, p<.001, r$ $=.30$. After controlling for the effect of economic status, a statistically significant effect of mobility remained for the TAKS reading scores, $F(1,240910)=412.92, p<.001$, partial $\eta^{2}=.002$; TAKS Mathematics scores, $F(1,240910)=631.03, p<.001$, partial $\eta^{2}=.003$; and for the TAKS Writing scores, $F(1,240910)=362.39, p<.001$, partial $\eta^{2}=.002$.

For research question $b$ for each subject area, the MANOVA revealed a statistically significant difference between mobile and non-mobile Grade 7 students in their overall achievement, Wilks' $\Lambda=1.0$, $p<.001$, partial $\eta^{2}=.004$, trivial effect size (Cohen, 1988). Follow-up ANOVA procedures also yielded statistically significant differences between mobile and non-mobile Grade 7 students in their TAKS Reading performance, $F(1,240910)=646.38, p<.001$, partial $\eta^{2}=.003$; in their TAKS Mathematics performance, $F(1,240910)=898.29, p<.001$, partial $\eta^{2}=.004$; and in their TAKS Writing performance, $F(1,240910)=564.898, p<.001$, partial $\eta^{2}=.002$.

Similar to the previous five years, non-mobile students had higher average TAKS Reading, Mathematics, and Writing test scores in the 2007-2008 school year than their mobile counterparts. These results remained even when controlling for economic status. Cohen's $d$ indicated a small effect size for reading (i.e., 0.40), a moderate effect size for mathematics (i.e., 0.51), and a small effect size for writing (i.e., 0.37; Cohen, 1988). The average TAKS Reading test raw score for mobile students was 3.08 points lower than the average TAKS Reading test raw score for non-mobile students. Concerning the TAKS Mathematics exam, the average raw score for mobile students was 4.82 points lower than the average raw score for non-mobile students. Regarding the TAKS Writing exam, the average raw score for mobile students was 2.11 points lower than the average raw score for non-mobile students. Table 6 contains the descriptive statistics for Grade 7 TAKS Reading, Mathematics, and Writing scores by mobility and economic status for the 2007-2008 school year.

Table 6. Descriptive statistics for grade 7 TAKS reading, mathematics, and writing tests for mobile and nonmobile students for the 2007-2008 school year

\begin{tabular}{l|l|l|l}
\hline TAKS Test by Mobility Status & $n$ & $M$ & $S D$ \\
\hline Reading & & & \\
\hline Non-Mobile & 237,642 & 40.58 & 6.84 \\
\hline Mobile & 3,268 & 37.50 & 8.49 \\
\hline Mathematics & & & \\
\hline Non-Mobile & 237,642 & 35.32 & 9.06 \\
\hline Mobile & 3,268 & 30.53 & 9.76 \\
\hline Writing & & & \\
\hline Non-Mobile & 237,642 & 34.26 & 5.02 \\
\hline
\end{tabular}




\begin{tabular}{l|l|l|l}
\hline Mobile & 3,268 & 32.15 & 6.20 \\
\hline
\end{tabular}

\section{Discussion}

The relationship between student mobility and academic achievement for Grade 7 students was examined in this study for the 2002-2003 through the 2007-2008 school years with and without controlling for economic status. Data were obtained from the Texas Education Agency Public Education Information Management System for all Texas Grade 7 students who were in the accountability subset for a school district. Statistically significant results were present in each school year, both when controlling for economic status and when not controlling for economic status. Trends for each subject area test were determined following the statistical analyses.

Across the six school years of statewide data analyzed in this study, non-mobile students had higher average TAKS Reading test scores than mobile students in each school year. The difference in reading scores between non-mobile students and mobile students ranged from 1.93 points to 3.15 points. To evaluate the relative difference between these two groups across the school years, a Cohen's $d$ was calculated for each year. These values are delineated in Table 7 and range from a high of 0.42 to a low of 0.25 . As such, these effect sizes were in the small range (Cohen, 1988).

Table 7. Cohen's ds for grade7 TAKS reading differences between mobile and non-mobile students for the 20022003 through the 2007-2008 school years

\begin{tabular}{l|l|l|l}
\hline School Year & $d$ & Effect Size Range & Lowest Performing Group \\
\hline $2002-2003$ & 0.25 & Small & Mobile \\
\hline $2003-2004$ & 0.33 & Small & Mobile \\
\hline $2004-2005$ & 0.35 & Small & Mobile \\
\hline $2005-2006$ & 0.42 & Small & Mobile \\
\hline $2006-2007$ & 0.40 & Small & Mobile \\
\hline $2007-2008$ & 0.40 & Small & Mobile \\
\hline
\end{tabular}

Differences between non-mobile and mobile students were not as large for the TAKS Reading assessment as they were for the TAKS Mathematics test. Across the six school years of data analyzed in this study, non-mobile students had higher average TAKS Mathematics raw scores than did mobile students in each school year. Average differences between non-mobile students and mobile students ranged from 2.57 points to 4.79 points. To determine the practical importance of these differences, a Cohen's $d$ was calculated for each school year. Table 8 contains the values for these Cohen $d$ s, which ranged from 0.28 to 0.53 . Effect size values at 0.50 or above were moderate whereas the effect sizes below 0.50 were small (Cohen, 1988).

Table 8. Cohen's ds for grade 7 TAKS mathematics differences between mobile and non-mobile students for the 2002-2003 through the 2007-2008 school years

\begin{tabular}{l|l|l|l}
\hline School Year & $d$ & Effect Size Range & Lowest Performing Group \\
\hline $2002-2003$ & 0.28 & Small & Mobile \\
\hline $2003-2004$ & 0.41 & Small & Mobile \\
\hline $2004-2005$ & 0.41 & Small & Mobile \\
\hline $2005-2006$ & 0.53 & Moderate & Mobile \\
\hline $2006-2007$ & 0.52 & Moderate & Mobile \\
\hline $2007-2008$ & 0.51 & Moderate & Mobile \\
\hline
\end{tabular}

The smallest differences between mobile and non-mobile students existed in the TAKS Writing scores. Across the six years of data analyzed differences in group means ranged from 1.66 points to 2.42 points. Similar to the TAKS Reading and TAKS Mathematics, non-mobile students had higher scores than 
mobile students. Cohen's $d s$ were calculated for each school year to determine the practical importance of these differences. Cohen's $d$ values for this study are presented in Table 9 and ranged from 0.24 to 0.39. These values were all reflective of small effect sizes (Cohen, 1988).

Table 9. Cohen's ds for grade 7 TAKS writing differences between mobile and non-mobile students for the 20022003 through the 2007-2008 school years

\begin{tabular}{l|l|l|l}
\hline School Year & $d$ & Effect Size Range & Lowest Performing Group \\
\hline $2002-2003$ & 0.24 & Small & Mobile \\
\hline $2003-2004$ & 0.35 & Small & Mobile \\
\hline $2004-2005$ & 0.32 & Small & Mobile \\
\hline $2005-2006$ & 0.37 & Small & Mobile \\
\hline $2006-2007$ & 0.39 & Small & Mobile \\
\hline $2007-2008$ & 0.37 & Small & Mobile \\
\hline
\end{tabular}

\subsection{Implications for Policy and Practice}

In Texas, schools are held accountable for a particular group of students referred to as their accountability subset. This accountability is realized through school ratings and punitive measures. Students who constitute the accountability subset in Texas are those students who are enrolled in a campus or district on the last Friday in October (i.e., Snapshot Day) and take the state standardized assessment (i.e., formerly the TAKS and now the State of Texas Assessments of Academic Readiness). Mobile students are those students who are enrolled at a campus less than $83 \%$ of the school year. Students with the greatest mobility are not included in the school's accountability subset, however some mobile students will be included in that accountability subset.

The definitions of a mobile student and parameters for a school's accountability subset create two subsets of mobile students. The first subset consists of students who are mobile, but are still included in an accountability subset. The second subset is comprised of mobile students who are not included in a school's accountability subset. The parameters for the accountability subset in Texas take in to account research literature regarding the existence of groups of students who are so mobile no single school has an opportunity to have an effect on them (Kerbow, 1995). The parameters of the accountability subset exclude the most mobile students. Over $99 \%$ of these students were also excluded from this study as their TAKS scores were not present in the data set. This adjustment appears to be effective in mitigating the effects of the most mobile students on a campus as gauged by the persistence of a difference in the academic achievement of mobile and non-mobile students but small effect sizes. However, excluding these students from the accountability subset creates incentives for not providing academic interventions for these students when scarcity in resources exists (Scherrer, 2013).

\subsection{Connections with Existing Literature}

The statistically significant differences between non-mobile students and mobile students in their reading and mathematics performance in each of the six years of data analyzed herein, when controlling for and not controlling for economic status, are congruent with the research literature that mobility negatively influences academic achievement (e.g., Audette, Algozzine, \& Warden, 1993; Hanushek et al., 2004, 2009; Kerbow, 1995; Lovell \& Isaacs, 2008; Reynolds et al., 2009; Schaller, 1975; Scherrer, 2013; Smith et al., 2008). Results, including a consideration of students included in this study and excluded due to a lack of scores, are also commensurate with other research finding about student mobility. The exclusion of the most mobile students from the accountability subset may allow the needs of the most mobile students to be neglected and at the same time these students may be in the most need of academic assistance.

As previously discussed, the definition of mobile students in Texas and the accountability subset create different classes of student mobility. Previously, researchers (e.g., Alexander, Entwisle, \& Dauber, 1996) have documented that different types of students exhibit different types of mobility. Lower income students tend to move within a district and from low performing school to low performing school 
whereas more affluent students leave low performing districts for higher performing districts, and, as a result, experience improvements in their academic achievement (Hanushek et al., 2004, 2009). Researchers (e.g., Boroque, 2009; Hanushek et al., 2004, 2009; Hartman, 2003; Reynolds et al., 2009; Smith et al., 2008) have also established that more mobile students (i.e., students who move more frequently) experience greater negative effects of mobility than do students who move less frequently. Unintended consequences of accountability systems can be that students not included in the accountability system do not receive interventions that they need if they are in competition with students who are included in the accountability system (Scherrer, 2013).

\subsection{Recommendations for Future Research}

Represented in Table 10 are students who were enrolled in Texas schools during the school years of data analyzed herein. Over 3,000 Grade 7 students per year were excluded from the study because their test scores were not included in the data set. The excluded students were predominantly mobile students.

Table 10. Sample group sizes for grade 7 not included students

\begin{tabular}{l|l|l|l|l|l}
\hline \multirow{2}{*}{ Year } & \multirow{2}{*}{$\begin{array}{l}\text { Total Cases } \\
\text { in Data Set }\end{array}$} & \multicolumn{4}{|l|}{ Not Included } \\
\cline { 3 - 6 } & & $\begin{array}{l}\text { Mobile } \\
\text { Accountability } \\
\text { Subset }\end{array}$ & $\begin{array}{l}\text { Non Accountability } \\
\text { Subset }\end{array}$ & $\begin{array}{l}\text { Accountability } \\
\text { Subset }\end{array}$ & $\begin{array}{l}\text { Non Accountability } \\
\text { Subset }\end{array}$ \\
\hline 2003 & 297,292 & 4,551 & 14,261 & 61,108 & 477 \\
\hline 2004 & 307,871 & 3,627 & 13,924 & 63,502 & 635 \\
\hline 2005 & 310,928 & 4,528 & 13,937 & 63,688 & 342 \\
\hline 2006 & 312,137 & 4,670 & 15,132 & 60,269 & 395 \\
\hline 2007 & 306,237 & 4,065 & 13,436 & 60,125 & 315 \\
\hline 2008 & 335,041 & 4,241 & 15,218 & 74,349 & 323 \\
\hline
\end{tabular}

Presented in Table 11 are the students who were included in the study. In the case of mobile students more students were not included in the study than were the numbers of mobile students. Very few students who were not included in an accountability subset had scores included in the data set utilized for this study.

Table 11. Sample group sizes for grade 7 included students

\begin{tabular}{|c|c|c|c|c|c|}
\hline \multirow{3}{*}{ Year } & \multirow{3}{*}{$\begin{array}{l}\text { Total } \\
\text { Cases } \\
\text { In Data } \\
\text { Set }\end{array}$} & \multicolumn{4}{|l|}{ Included } \\
\hline & & \multicolumn{2}{|l|}{ Mobile } & \multicolumn{2}{|l|}{ Not-Mobile } \\
\hline & & $\begin{array}{l}\text { Accountability } \\
\text { Subset }\end{array}$ & $\begin{array}{l}\text { Non Accountability } \\
\text { Subset }\end{array}$ & $\begin{array}{l}\text { Accountability } \\
\text { Subset }\end{array}$ & $\begin{array}{l}\text { Non Accountability } \\
\text { Subset }\end{array}$ \\
\hline 2003 & 297,292 & 4,101 & 28 & 212,762 & 4 \\
\hline 2004 & 307,871 & 2,794 & 68 & 223,321 & 0 \\
\hline 2005 & 310,928 & 4,527 & 38 & 223,865 & 3 \\
\hline 2006 & 312,137 & 4,683 & 50 & 226,935 & 3 \\
\hline 2007 & 306,237 & 3,705 & 31 & 224,559 & 1 \\
\hline 2008 & 335,041 & 3,196 & 72 & 237,642 & 0 \\
\hline
\end{tabular}

Prior academic achievement has also been reported to have an effect on the academic outcomes of mobile students (e.g., Heinlein \& Shinn, 2000; Reynolds et al., 2009; Strand \& Demie, 2007). Connecting academic achievement for students across moves, years, and possible testing changes is difficult. As improvements in tracking students have occurred a more recent data set may be better able to connect students across moves. Researchers considering student prior academic achievement could contribute to the mobility knowledge base. 
Demographic characteristics of students may also have an effect on the academic achievement outcomes for mobile students. Researchers are encouraged to undertake studies in which student gender is analyzed to determine the degree to which differences might be present in the academic achievement of mobile boys and girls. Another variable that needs to be addressed is the relationship of mobility and student ethnicity/race and academic achievement. The degree to which mobility has similar results for Asian, White, Hispanic, and Black students is not known. Finally, it is recommended that researchers investigate the academic achievement of other middle grade level (i.e., Grade 6 and Grade 8) mobile students.

The relationship between the negative effects of mobility and the negative effects of economic disadvantage has been frequently debated. Measures to mitigate the effects of mobile students on a school's ratings have been implemented in Texas; however, these measures also eliminate many of mobile students from this study. In this multiyear, statewide analysis, Grade 7 mobile students had lower academic achievement in reading, mathematics, and writing than their non-mobile counterparts. The greatest differences in performance were attributable to student economic status. However, even when economic status was controlled, mobile students continued to have lower test scores than their non-mobile counterparts. More research is needed in which data at other middle level grades and containing a larger percentage of students not included in an accountability subset are analyzed.

\section{References}

1. Alexander, K. L., Entwisle, D. R., \& Dauber, S. L. (1996). Children in motion: School transfers and elementary school performance. The Journal of Education Research, 90, 3-12. doi:10.1080/00220671.1996.994443.

2. Audette, R., Algozzine, R., \& Warden, M. (1993). Mobility and school achievement. Psychological Reports, 72, 701-702.

3. Bourque, M. M. (2009). The impact of student mobility on academic achievement: Lessons learned in the time of the Boston University/Chelsea Public Schools partnership. In C. S. Candal, (Ed.), Partnering for progress: Boston University, Chelsea Schools, and urban education reform (pp. 65-88). Charlotte, NC: Information Age Publishing.

4. Bradshaw, C. P., Sudhinaraset, M., Mmari, K., \& Blum, R. W. (2010). School transitions among military adolescents: A qualitative study of stress and coping. School Psychology Review, 39, 84-105.

5. Branz-Spall, A. M., Rosenthal, R., \& Wright, A. (2003). Children of the road: Migrant students, our nation's most mobile population. Journal of Negro Education, 72, 55-62. doi:10.2307/3211290.

6. Bruno, J. E., \& Isken, J. A. (1996). Inter- and intra-school site student transiency: Practical and theoretical implications for instructional continuity at inner city schools. Journal of Research and Development in Education, 29, 239-252.

7. Cohen, J. (1988). Statistical power analysis for the behavioral sciences (2nd ed.). Hillsdale, NJ: Lawrence Erlbaum.

8. Field, A. (2009). Discovering statistics using SPSS: Introducing statistical methods (3rd ed). Thousand Oaks, CA: Sage.

9. Franke, T. M., Isken, J. A., \& Para, M. T. (2003). A pervasive school culture for the betterment of student outcomes: One school's approach to student mobility. Journal of Negro Education, 72, 150-157.

10.Gasper, J., DeLuca, S., \& Estacion, A. (2010). Coming and going: Explaining the effects of residential and school mobility on adolescent delinquency. Social Science Research, 39, 459-476. doi:10.1016/j.ssresearch.2009.08.009.

11.Hanushek, E. A., Kain, J. F., \& Rivkin, S. G. (2004). Disruption versus Tiebout improvement: The costs and benefits of switching schools. Journal of Public Economics, 88, 1721-1746.

12.Hanushek, E. A., Kain, J. F., \& Rivkin, S. G. (2009). Corrigendum to "Disruption versus Tiebout improvement: The costs and benefits of switching schools." Journal of Public Economics, 93, 1283-1284. doi:10.1016/j.jpubeco.2009.08.003

13.Hartman, C. (2003). Introduction and overview: Student mobility: How some children get left behind. Journal of Negro Education, 72, 1-5. doi:10.2307/3211286.

14.Haveman, R., \& Wolfe, B. (1994). Succeeding generations: On the effects of investing in children. New York, NY: Russell Sage Foundation. 
15.Haynie, D. L., South, S. J., \& Bose, S. (2006). The company you keep: Adolescent mobility and peer behavior. Sociological Inquiry, 76, 397-426. doi:10.111/j.1475-682X.2006.00161.x.

16.Heinlein, L. M., \& Shinn, M. (2000). School mobility and student achievement in an urban setting. Psychology in the Schools, 37, 349-357. doi:10.1002/1520-6807(200007)37:4<359::AID-PITS6>3.0.CO;2-1.

17.James, B. W., \& Lopez, P. D. (2003). Transporting homeless students to increase stability: A case study of two Texas districts. Journal of Negro Education, 72, 126-140. doi:10.2307/3211296.

18.Johnson, R. B., \& Christensen, L. B. (2008). Educational research: Quantitative, qualitative, and mixed approaches (3rd ed.). Thousand Oaks, CA: Sage.

19.Julianelle, P. F., \& Foscarinis, M. (2003). Responding to the school mobility of children and youth experiencing homelessness: The McKinney-Vento Act and beyond. Journal of Negro Education, 72, 39-54. doi:10.2307/3211289.

20.Kain, J. F., \& O'Brien, D. M. (1998). A longitudinal assessment of reading achievement: Evidence for the Harvard/UTD Texas schools project. Dallas, TX: University of Texas - Dallas.

21.Kerbow, D. (1995). Pervasive student mobility: A moving target for school reform. Chicago, IL: Chicago Panel on School Policy.

22.Kerbow, D., Azcoita, C., \& Buell, B. (2003). Student mobility and local school improvement in Chicago. Journal of Negro Education, 72, 158-164. doi:10.2307/3211299.

23.Lovell, P., \& Isaacs, J. (April, 2008). The impact of the mortgage crisis on children and their education. First Focus, 1-5.

24.Pribesh, S., \& Downey, D. B. (1999). Why are residential and school moves associated with poor school performance? Demography, 36, 521-534.

25.Reynolds, A. J., Chen, C., \& Herbers, J. E. (2009, June). School mobility and educational success: A research synthesis and evidence on prevention. Paper presented at the Workshop on the Impact of Mobility and Change on the Lives of Young Children, Schools, and Neighborhoods, Washington, DC.

26.Ross, L. S. (2014). The influence of the student mobility rate on the graduation rate in the state of New Jersey. (Doctoral dissertation). Available from ProQuest Dissertations and Thesis database. (UMI No. 1658215993)

27.Rumberger, R. W. (2003). The causes and consequences of student mobility. Journal of Negro Education, 72, 621. doi: $10.2307 / 3211287$.

28.Rumberger, R. W., Larson, K. A., Ream, R., \& Palardy, G. (1999). The educational consequences of mobility for California students and schools. Report prepared for Policy Analysis for California Education, PACE, University of California Berkley \& Stanford University, Berkley, CA.

29.Schaller, J. (1975). The relationship between geographic mobility and school behavior. Man-Environment Systems, 5, 185-187.

30.Scherrer, J. (2013). The negative effects of student mobility: Mobility as a predictor, mobility as a mediator. International Journal of Educational Policy and Leadership, 8(1), 1-14. Retrieved from ijepl.org.

31.Smith, J. L. M., Fein, H., \& Paine, S. C. (2008). When mobility disrupts learning. Educational Leadership, 65(7), 59-63.

32.Smrekar, C. E., \& Owens, D. E. (2003). It's a way of life for us, high mobility and high achievement in Department of Defense schools. Journal of Negro Education, 72, 165-177. doi:10.2307/3211300.

33.Strand, S., \& Demie, F. (2007). Pupil mobility, attainment, and progress in secondary school. Educational Studies, 33(3), 317-331.

34.Temple, J., \& Reynolds, A. J. (1999). School mobility and achievement: Longitudinal findings from an urban cohort. Sociology of Education, 71, 355-377. doi:10.1016/S0022-4405(99)00026-6.

35.Texas Education Agency. (2012). Glossary for the Academic Excellence Indicator System. Retrieved from http://ritter.tea.state.tx.us/perfreport/aeis/2011/glossary.html. 